\title{
Sectoral co-movements in the Indian stock market: A mesoscopic network analysis
}

\author{
Kiran Sharma* Shreyansh Shah ${ }^{\dagger} \quad$ Anindya S. Chakrabarti ${ }^{\ddagger}$ \\ Anirban Chakraborti §
}

July 20, 2016

\begin{abstract}
In this article we review several techniques to extract information from stock market data. We discuss recurrence analysis of time series, decomposition of aggregate correlation matrices to study co-movements in financial data, stock level partial correlations with market indices, multidimensional scaling and minimum spanning tree. We apply these techniques to daily return time series from the Indian stock market. The analysis allows us to construct networks based on correlation matrices of individual stocks in one hand and on the other, we discuss dynamics of market indices. Thus both micro level and macro level dynamics can be analyzed using such tools. We use the multi-dimensional scaling methods to visualize the sectoral structure of the stock market, and analyze the comovements among the sectoral stocks. Finally, we construct a mesoscopic network based on sectoral indices. Minimum spanning tree technique is seen to be extremely useful in order to separate technologically related sectors and the mapping corresponds to actual production relationship to a reasonable extent.
\end{abstract}

\section{Introduction}

In this paper, we present a coherent analysis of the Indian stock market employing several techniques recently proposed in the econophysics literature. Stock market is a fascinating example of a rapidly evolving multi-agent interacting system that generates an enormous amount of very well defined and well documented data. Because of the sheer volume of data, it becomes possible to construct large scale correlation matrices across stocks that contain information about the aggregate market. Thus the loss of information due to aggregation can be minimized to a great extent. Several useful

\footnotetext{
${ }^{*}$ School of Computational and Integrative Sciences, Jawaharlal Nehru University, New Delhi-110067, India. Email: kiran34_sit@jnu.ac.in

${ }^{\dagger}$ Indian Institute of Technology, Banaras Hindu University, Varanasi-221005, India. Email: shreyansh.shah.mec13@iitbhu.ac.in

${ }^{\ddagger}$ Economics area, Indian Institute of Management, Vastrapur, Ahmedabad, Gujarat-380015, India, Email: anindyac@iima.ac.in.

${ }^{\S}$ School of Computational and Integrative Sciences, Jawaharlal Nehru University, New Delhi-110067, India, Email: anirban@jnu.ac.in
} 
techniques to analyze such large-scale data have been proposed and there are multiple resources reviewing them. Interested readers can refer to [5] and [6] for excellent and quite extensive textbook expositions.

We present a series of analysis on the Bombay stock exchange, using both macro scale and micro scale data. Even though there are separate attempts in a few other papers that presented analysis on similar data sets, this probably is the first attempt to systematically analyze Indian stock market data in a comprehensive manner. At the beginning of discussion on every technique, we point out the papers that proposed the techniques and subsequent analysis, if any, on Indian or any other emerging market data. India being an emerging market is an interesting example. Several papers (Ref. [10], [2]) have pointed out that there are systematic differences between the dynamic behavior of developed economies and emerging economies.

\section{Nonlinear dynamics: recurrence plot analysis}

For a very long time it had been conjectured that the stock market indices may have certain features of a highly nonlinear dynamical system. It originated from certain speculations that economic systems in general may show chaotic behavior (see e.g. [7]). [8] considered an idea that the aggregate macro dynamics of an economy may show chaotic behavior. By and large, such thoeries are no longer considered to be useful descriptions of economic dynamics. However, in recent times there have been some attempts to analyze the stock index behavior by using recurrence analysis based on phase space reconstruction.

In general, the technique's usefulness comes from the fact that it is non-parametric, does not make any assumptions about the data and can work with non-stationary data. In particular, the technique is useful for detecting sudden large change in a time series. A stock market crash has often been thought of as a phase transition indicating a large abrupt change in the behavior [12]. However, the technique is useful for recovering patterns in potentially highly nonlinear but recursive systems, an assumption that is not satisfied by the stock market. We follow the mode of analysis presented in details in [11] and [10].

Here we describe construction of recurrence plots. It is based on the idea of recurrence within a phase space and the plot exhibits times when a nonlinear system revisits the same phase space during the process of evolution. Consider a time series $\{x(i)\}_{i=1}^{N}$ representing an index of a stock market. We know from Takens' theorem [9] that it is possible to extract information about the phase space from the time series (see also Ref. [10]). We start by embedding $\{x\}$ into an $m$ dimensional space given by,

$$
y(i)=[x(i), x(i+\delta), x(i+2 \delta), \ldots, x(i+(m-1) \delta)]
$$

where, $d$ is the time delay. Together these two parameters constitute the set of embedding parameters. Thus $y(i)$ is a point in the $m$ dimensional Euclidean space, representing the evolution of the system in the reconstructed phase space. We collect all such $y(i)$ 's and present element-by-element 

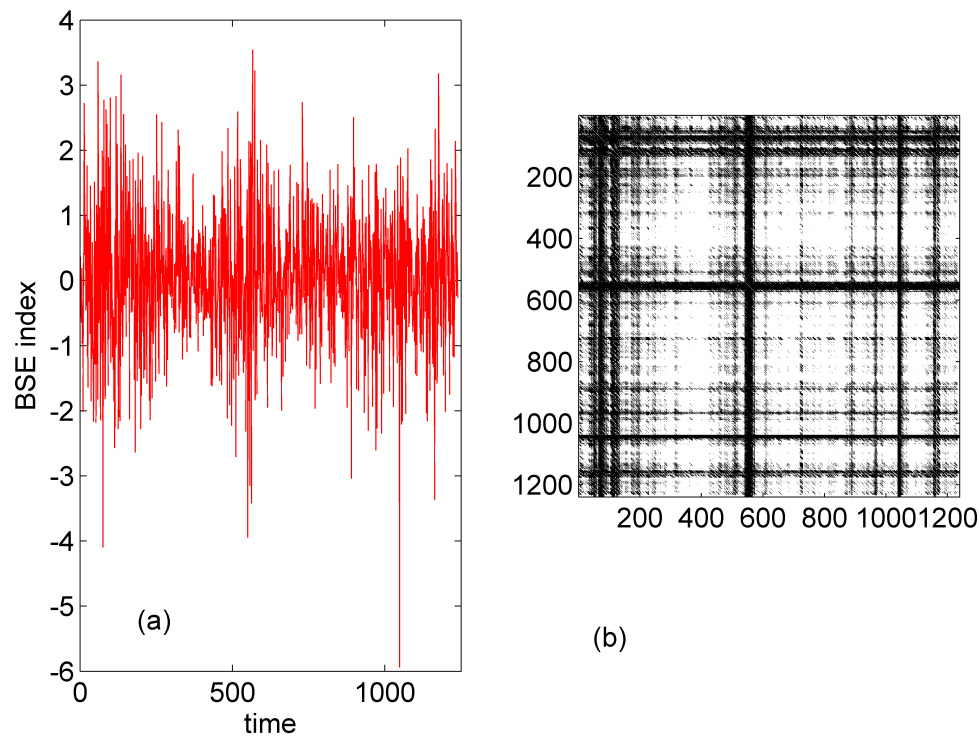

(b)

Figure 1: Left panel: Normalized daily return series constructed from BSE index data for five years (6th June, 2011 to 6th June, 2016). Right panel: Recurrence plot constructed from the same data with an embedding dimension equals to 11 and time delay 1.
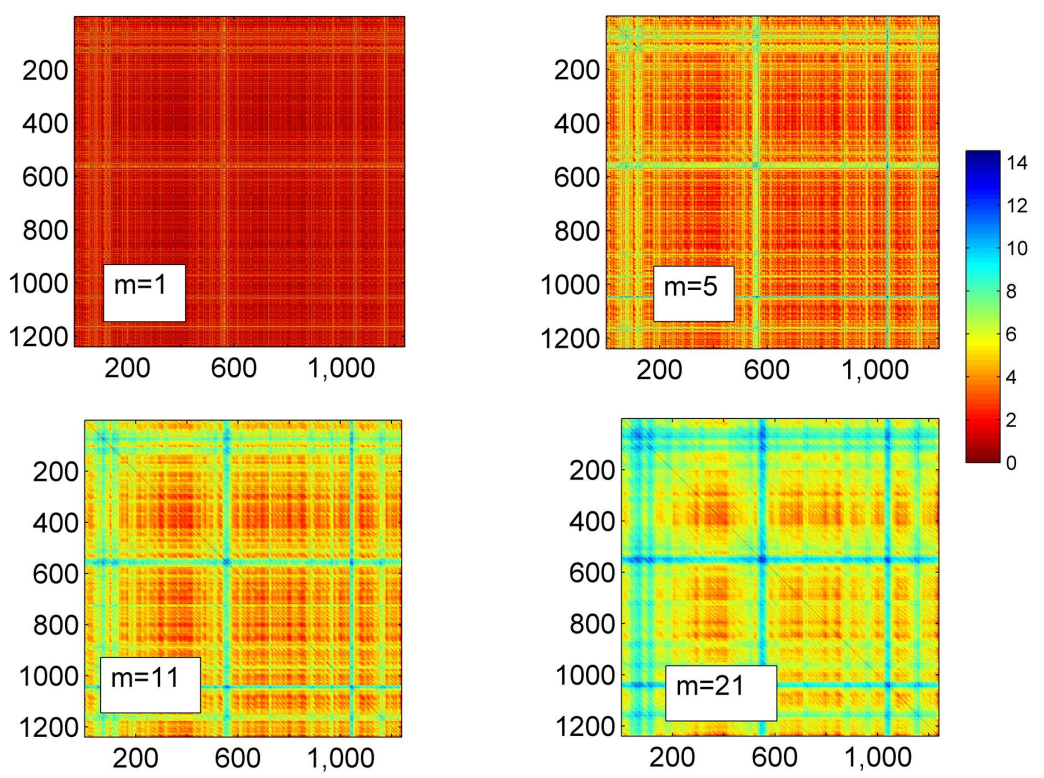

Figure 2: Distance plots constructed from the BSE index for different values of the embedding dimensions $(m=2,5,11,21)$. 
difference with Euclidean norm to create a two dimensional plot. Such a plot exhibits if there is any recurrence as explained below.

Let us define a matrix $R$ such that its $i, j$-th element $(i, j=1, \ldots, n$, with $n=N-(m-1) d)$ is expressed as

$$
R_{i j}(\epsilon)=\left\{\begin{array}{l}
0 \text { if }|y(i)-y(j)|>\epsilon \\
1 \text { if }|y(i)-y(j)| \leq \epsilon
\end{array}\right.
$$

where $\|$.$\| is the Euclidean norm, and \epsilon$ is the threshold applied which is a positive real number. Recurrence plots are exactly symmetric along the diagonal.

\section{Inference based on structures:}

In recurrence plots, we see multiple patterns including dots, diagonal as well as vertical and horizontal lines and all possible combinations of them.

- Isolated points exist if states are rare or persistence is low or if they represent high fluctuations.

- Existence of a diagonal line $R_{i+m, j+m}=1$ (for $m=1, \ldots, l$ where $l$ is the length of the diagonal line) indicates presence of recurrence i.e. a segment of the time series revisits the same area in the phase space at a lag. If there are lines parallel to the line of identity, it represents the parallel evolution of trajectories.

- Existence of a vertical (horizontal) line $R_{i, j+m}=1$ (for $m=1, \ldots, v$ where $v$ is the length of the line) indicates a stage during evolution where the system gets trapped for some time and does not evolve fast. This can be an intermittent behavior.

Now we conduct recurrence quantification analysis (RQA) by studying the structure of the plots numerically. Such an analysis is based essentially on densities of isolated points, diagonal lines as well as vertical lines. We borrow the discussion presented below from [10]. The measures which we have considered are as follows:

- RR: Recurrence rate.

- DET: Fraction of points in the plot forming diagonal lines. This indicates determinism and hence, predictability.

- $\langle L\rangle$ : Average lengths of the diagonal lines.

- LMAX: Length of the longest diagonal line (except the line of identity). Its inverse is associated with the divergence of the trajectory in phase-space.

- ENTR: Shannon entropy defined over the distribution of lengths of diagonal lines, indicates diversity of the diagonal lines.

- LAM: Fraction of points forming vertical lines, indicates existence of laminar states in the system. 


\begin{tabular}{|c|c|c|c|c|}
\hline Quantity & $m=1$ & $m=2$ & $m=5$ & $m=11$ \\
\hline \hline RR & 0.0758 & 0.0442 & 0.0075 & $3.1049 \times 10^{-4}$ \\
\hline DET & 0.9029 & 0.8817 & 0.8516 & 0.9211 \\
\hline$\langle L\rangle$ & 4.3854 & 3.9302 & 3.8841 & 4.6667 \\
\hline LMAX & 146 & 88 & 58 & 18 \\
\hline ENTR & 2.0319 & 1.8575 & 1.8095 & 1.8527 \\
\hline LAM & 0.9479 & 0.9074 & 0.7234 & 0.2763 \\
\hline TT & 5.7416 & 4.4451 & 3.2874 & 2.2703 \\
\hline
\end{tabular}

Table 1: Measures based on recurrence analysis of normalized BSE data. Generated by the CRP toolbox (Ref. [3] and [4]). Threshold for calculating neighbors set at the default value 0.1.

- TT: Average length of the vertical lines, this value estimates the trapping time.

We have computed the RQA measures for the BSE index under a range of embedding dimension. In each case, we have set the delay equal to 1 . In Fig. 1 and 2 we present recurrence analysis on logarithmic return series $\left(r_{\tau}=\ln P_{\tau}-\ln P_{\tau-1}\right)$ constructed from BSE index data. As is apparent, there is no clearly discernible pattern in the data. Next, we follow the standard approach and use the level of the price data upon normalization by the maximum value of the time series $\left(\tilde{P}_{\tau}=\right.$ $\left.\left(P_{\tau}-P_{\min }\right) / P_{\max }\right)$. Table 1 contains the RQA measures. Most of the prior literature on stock market data consider high values of embedding parameter. It is evident that, in general, recurrence rates are very low and determinism is very high. However, this approach has an inherent problem that it is not particularly good at differentiating non-recursive series from recursive series. In general, we found that when we construct similar measures for standard recursive series, it is not clear from such RQA measures that they can be easily separated from a stochastic series. Thus it does not really shed much light on the problem as the primary focus is to figure out determinism or lack thereof. Ref. [10] discusses a possible application that these measures still retain some usefulness for cross-country analysis. Since in this case we are focusing on one country only, it is not very helpful. So we consider a fully stochastic framework in the rest of the analysis.

\section{Empirical study of the correlation structure of the Indian stock market}

In this section, we analyze the empirical cross-correlation matrices constructed from the stock market data.

\subsection{Data specification, notations, and definitions}

In order to study correlations and co-movements in the stock price time series, the popular Pearson correlation coefficient was commonly used. However, with the electronic markets producing data at different frequencies (low to high), it is now known that several factors viz., the statistical uncertainty associated with the finite-size time series, heterogeneity of stocks, heterogeneity of 

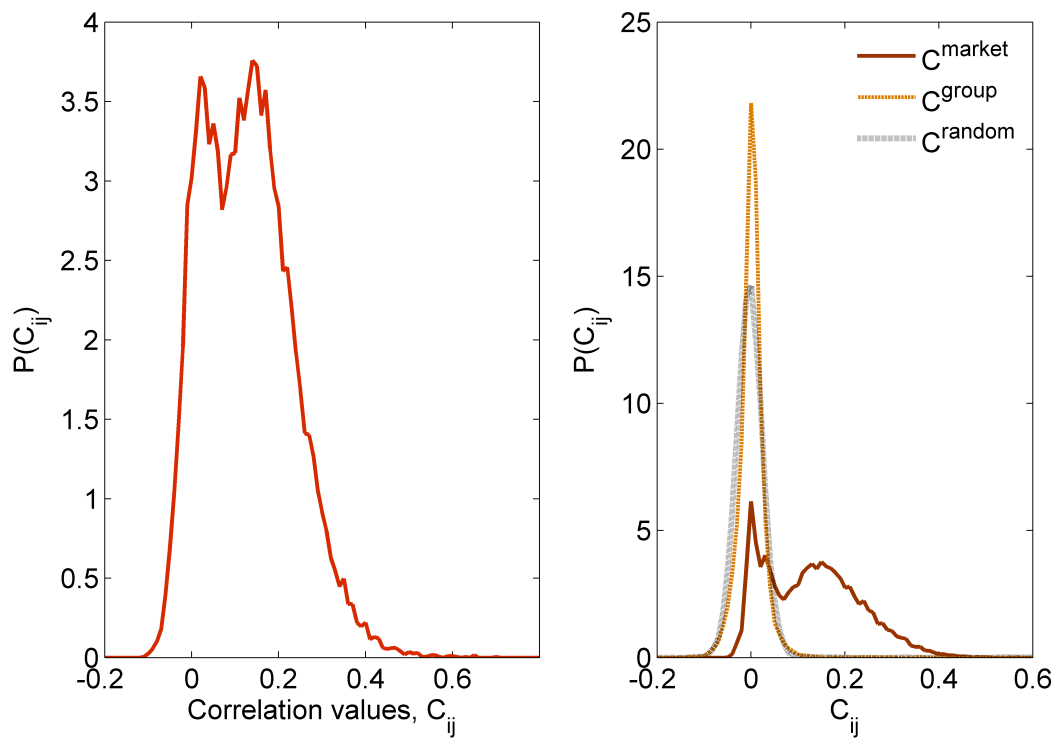

Figure 3: Left panel: Probability density function of the cross-correlation coefficients of 199 BSE stocks. Right panel: Decomposition of the correlation matrix into market mode, group mode and random mode.

the average inter-transaction times, and asynchronicity of the transactions may affect the applicability/reliability of this estimator. In this article, we have mainly focused on the daily returns computed from closure prices, for which the Pearson coefficient works well.

\subsubsection{Data set}

We have used the freely download able daily adjusted closure prices from Yahoo finance for $N=$ 199 companies in the Bombay Stock Exchange (BSE) SENSEX [14], for five years, over a period spanning from June 6, 2011 to June 6, 2016. Also we have downloaded 199 stock prices of companies chosen randomly from the BSE and 13 sectoral indices of the BSE, for the period May 27, 2011 to May 27, 2016. The lists are given in the appendices I and II.

\subsection{Correlation matrices}

We construct the correlation matrix from individual stock returns in the following way.

\subsubsection{Pearson correlation coefficient}

In order to study the equal time cross-correlations between $N$ stocks, we first denote the adjusted closure price of stock $i$ in day $\tau$ by $P_{i}(\tau)$, and determine the logarithmic return of stock $i$ as $r_{i}(\tau)=\ln P_{i}(\tau)-\ln P_{i}(\tau-1)$. For the window of $T$ consecutive trading days, these returns form the return vector $r_{i}$. We use the equal time Pearson correlation coefficients between stocks $i$ and $j$ 

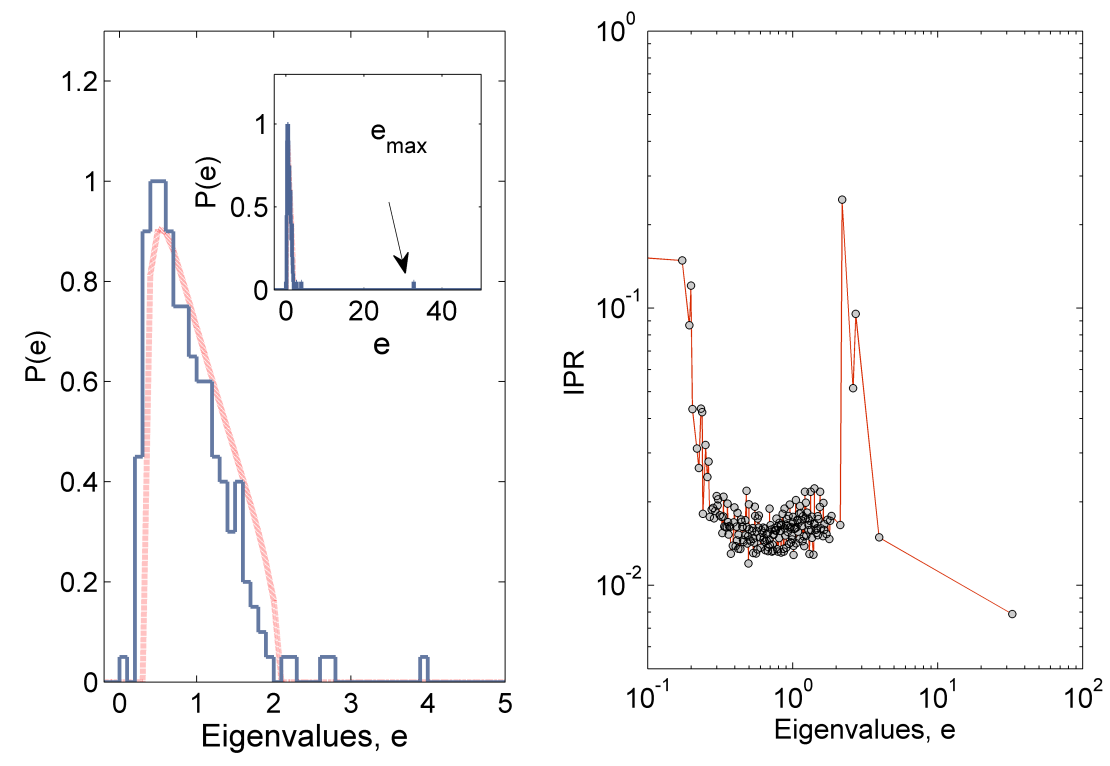

Figure 4: Eigenvalue decomposition of the correlation matrix. Left panel: Probability density function of eigenvalues. Inset shows the full distribution. Right panel: Inverse participation ratio with respect to the corresponding eigenvalues.

defined as

$$
C_{i j}=\frac{\left\langle r_{i} r_{j}\right\rangle-\left\langle r_{i}\right\rangle\left\langle r_{j}\right\rangle}{\sqrt{\left[\left\langle r_{i}^{2}\right\rangle-\left\langle r_{i}\right\rangle^{2}\right]\left[\left\langle r_{j}^{2}\right\rangle-\left\langle r_{j}\right\rangle^{2}\right]}},
$$

where $\langle\ldots\rangle$ indicates an average over the window of $T$ successive trading days in the return series. Naturally, such correlation coefficients satisfy the usual condition of $1 \leq C_{i j} \leq 1$ and we can create an $N \times N$ correlation matrix $C$ by collecting all values $[15,16]$. By construction, the matrix is symmetric and it serves as the basis of the rest of the present article.

\subsection{Decomposition analysis}

For the present section, we are following the sequence of methods discussed by Ref. [2] which is one of the first few papers that applied this technique. Suppose we have $N$ return time series of length $T$ that are pairwise uncorrelated. The correlation matrix generated by collecting all pairwise correlations for $N$ such series is called Wishart matrix. In the limit $N \rightarrow \infty$ and $T \rightarrow \infty$, such that the ratio $Q \equiv T / N>1$, the eigenvalue distribution of this matrix has a specific distributional form,

$$
f(\lambda)=(Q / 2 \pi) \frac{\sqrt{\left(\lambda_{\max }-\lambda\right)\left(\lambda-\lambda_{\min }\right)}}{\lambda},
$$

for $\lambda_{\min } \leq \lambda \leq \lambda_{\max }$ and, 0 otherwise. This distribution is clearly bounded by $\lambda_{\max , \min }=$ $[1 \pm(1 / \sqrt{Q})]^{2}$. In the BSE data we considered, $Q=5$. Thus the Wishart matrix should have the 
following bounds: $\lambda_{\min }=0.3056$ and $\lambda_{\max }=2.0944$. The distribution of eigenvalues unexplained by the Wishart matrix sheds light on the interaction structures and the coevolution process of the stocks in the market.

The largest eigenvalue corresponds to the market mode which captures the aggregate dynamics of the market that is common across all stocks. The eigenvectors associated with the next few eigenvalues (we took the next 5 dominant eigenvalues) describe the sectoral dynamics. The rest of the eigenvectors correspond to the random mode. From such a segregation, it is possible to reconstruct the contributions of different modes to the aggregate correlation matrix.

Following the literature to filter the data to remove market mode and the random noise, we first decompose the aggregate correlation matrix as

$$
C=\sum_{i=0}^{N-1} \lambda_{i} a_{i} a_{i}^{T},
$$

where $\lambda_{i}$ are the eigenvalues of the correlation matrix $C$. An easy way to handle the reconstruction of the correlation matrix is to sort the eigenvalues in descending order. Then we rearrange the eigenvectors $a_{i}$ in corresponding ranks. This allows us the decompose the matrix into three separate components viz. market, group and random:

$$
\begin{aligned}
C & =C^{M}+C^{G}+C^{R}, \\
& =\lambda_{0} a_{0} a_{0}^{T}+\sum_{i=1}^{N_{G}} \lambda_{i} a_{i} a_{i}^{T}+\sum_{i=N_{G}+1}^{N-1} \lambda_{i} a_{i} a_{i}^{T}
\end{aligned}
$$

where $N_{G}$ is taken to be 5 i.e. corresponds to the 5 largest eigenvalues except the first one. It is worth noting that the exact value of $N_{G}$ is not crucial for the result as long as it is kept within the same ballpark. The decomposition is shown in Fig. 3.

An important finding is that the group mode almost coincides with the random mode whereas the market mode is segregated by a large margin from the rest. Thus the sectoral dynamics are almost absent whereas the market mode is very strong. This is in line with the prior literature (see e.g. [2]).

Following standard procedure (see e.g. Ref. [2]), we also calculate the inverse participation ratio (IPR) to extract information about contribution of different stocks to the eigenvalues. IPR is defined for the $k$-th eigenvector as the sum of fourth power of all individual components of the corresponding eigenvector, $I_{k} \equiv \sum_{i=1}^{N}\left[a_{k i}\right]^{4}$, where $a_{k i}$ are the components of eigenvector $\mathrm{k}$. The result is presented in Fig. 4. Intuitively if a single stock dominates in terms of contribution to any particular eigenvector, then the $I P R$ would go to 1 . For example, consider a limiting case of $a_{k 1}=1$ and $a_{k i}=0$ for $i \neq 1$. On the other hand if all elements were equal to $1 / \sqrt{N}$, then we would get $I P R=1 / N$. Thus by considering IPR, we can understand if there is significant contribution coming from specific stocks or a more diversified bundle of stocks. 

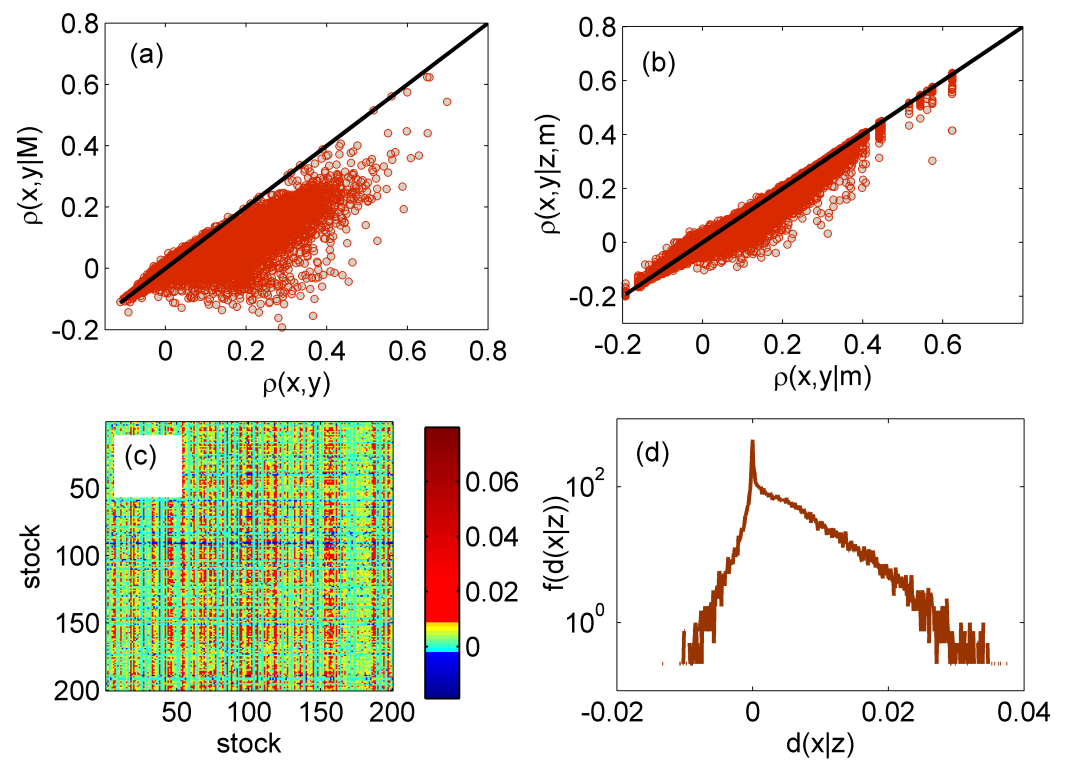

Figure 5: Correlation matrix after controlling for market mode (BSE index). Panel (a): Partial correlation after controlling for the market mode as a function of raw correlation coefficients. Panel (b): Same after controlling for the third variable effect. Panel (c): Influence of all stocks as the third variable (on $x$-axis) on all other stocks (on $y$-axis). Panel (d): Probability density function of average influence quantity.

\subsection{Partial correlation analysis}

Partial correlation is a newly introduced tool to investigate the effects of third stock on the correlation between a pair of stocks. [13] introduced this analysis for multiple stock markets. In the present paper we apply their technique to the Bombay stock exchange data. To describe its usefulness, consider 3 stocks, $i, j$ and $k$, with significant correlation between all three pairs of the stocks. Suppose, we think that the high value of $C_{i j}$ is the result of their own correlations with $k$, i.e. part of $C_{i j}$ might be spurious correlation arising from a third variable effect (in this case $k$ ), we should remove such effects to figure out the actual correlation across $i$ and $j$. Then we can recalculate $C_{i j}$, after controlling for the effect of $k$. The resultant correlation value is called the partial correlation. The difference between the raw correlation value between a pair of stocks and the corresponding partial correlation tells us how much third-variable effect was there.

For this purpose, we again use the same daily log return $r_{i}(t)$. However, we need to adjust for one more factor. From the preceding analysis, we already know that there is a significant market mode. Therefore, that will act a common driving factor. Hence, the market mode should also be controlled for in order to extract the actual correlation values for the exact same reason. In this case, the market mode is given by a market index. Note the difference from the earlier analysis. For constructing the market mode from the eigenvalue analysis, the market mode arise endogenously from the panel data itself whereas in this case, we take the market mode to be given by an exogenous 
index time series. Hence, these two types of analysis complement each other.

Following the notation of [13], let $x, y$ be two time series and let $M$ be the BSE index for the same time frame. The partial correlation, $(x, y \mid M)$ is defined as the standard Pearson correlation coefficient (described above) between $x$ and $y$ after controlling for $M$. More technically, this is the correlation between the residuals of $x$ and $y$ which are unexplained by the market index represented by $M$. So first, we need the residuals of the two time series. A simple way is to do it would be to regress both on M. Then we can work with the resulting variables. Formally, the correlation is given as

$$
C_{x, y \mid M}=\frac{\left(C_{x, y}-C_{x, M} \cdot C_{y, M}\right)}{\sqrt{\left[1-C_{x, M}^{2}\right] \cdot\left[1-C_{y, M}^{2}\right]}}
$$

In the same way, when the same two stocks $x$ and $y$ are affected by a common stock $z$, we can control for that effect as well. Given a third stock $z$, the partial correlation between $x$ and $y$ after controlling for both the market factor as well as that third stock $z$, is given by the following formula

$$
C_{x, y \mid M, z}=\frac{C_{x, y \mid M}-C_{x, z \mid M} \cdot C_{y, z \mid M}}{\sqrt{\left[1-C_{x, z \mid M}^{2}\right] \cdot\left[1-C_{y, z \mid M}^{2}\right]}}
$$

If it is found that the third stock has an important effect on pairs of stocks, then it is useful to define the 'Influence Quantity' (see [13])

$$
d(x, y \mid z)=C_{x, y \mid M}-C_{x, y \mid M, z}
$$

Magnitude of this quantity will reflect how much influence does the third stock influence on a pair of stocks. A natural extension of this idea is to consider the average influence $d(x \mid z)$ of stock $z$ on the correlations between a given stock $x$ and all other stocks except $x$ itself and $z$. Ref. [13] defined this index as the following

$$
d(x \mid z)=\langle d(x, y \mid z)\rangle_{y \neq x} .
$$

This quantity captures the average influence from stock $z$ to stock $x$ through the third variable effect after controlling for the market index.

We present all results of our analysis in Fig. 5. Panel (a) shows the correlation coefficients of all stocks after controlling for the market index. Since the bulk of it is below the $45^{\circ}$ line, we conclude that the market index has a positive effect on pairwise correlations. This is consistent with the results from the eigenvalue analysis and also with [13]. Similarly, in panel (b) we show the data for the same correlation coefficients after controlling for all possible third variable effects. In panel (d), we present the probability density function of the influence quantity. Again bulk of the distribution is in the positive quadrant implying positive effect on average.

\section{Network analysis}

In this section, we present network analysis based on the empirical correlation matrix. 


\subsection{Distance metric}

To obtain "distances", the following transformation

$$
d_{i j}=\sqrt{2\left(1-C_{i j}\right)}
$$

is used, which clearly satisfies $2 \geq d_{i j} \geq 0$. Collecting all distances one can form an $N \times N$ distance matrix $D$, such that all elements of the matrix are "ultrametric" [17]. The concept of ultrametricity appears in multiple papers. Interested readers can refer to the detailed discussions by Mantegna [18, 19, 20, 15] among others. There are multiple possible ultrametric spaces. We opt for the subdominant ultrametric, as it is simple to work with and and its associated topological properties. The choice of the non-linear function is again arbitrary, as long as all the conditions of ultrametricity are met.

\subsection{Multidimensional scaling (MDS)}

Multidimensional scaling is a method to analyze large scale data that displays the structure of similarity in terms of distances, given by Eq. 11, as a geometrical picture or map, where each stock corresponds to a set of coordinates in a multidimensional space. MDS arranges different stocks in this space according to the strength of the pairwise distances between stocks, - two similar stocks are represented by two set of coordinates that are close to each other, and two stocks behaving differently are placed far apart (see Ref. [21]) in the space. We construct a distance matrix consisting of $N \times N$ entries from the $N$ time series available, defined using Eq. 11:

$$
D=\left[\begin{array}{cccc}
d_{11} & d_{12} & \ldots & d_{1 N} \\
d_{21} & d_{22} & \ldots & d_{21} \\
\vdots & \vdots & \ddots & \vdots \\
d_{N 1} & d_{N 2} & \ldots & d_{N N}
\end{array}\right]
$$

Given $D$, the aim of MDS is to generate $N$ vectors $x_{1}, \ldots, x_{N} \in \Re^{D}$, such that

$$
\left\|x_{i}-x_{j}\right\| \approx d_{i j} \quad \forall i, j \in N
$$

where $\|$.$\| represents vector norm. We can use the Euclidean distance metric as is done in the$ classical MDS. Effectively, through MDS we try to find a mathematical embedding of the $N$ objects into $\Re^{D}$ by preserving distances. In general, we choose the embedding dimension $D$ to be 2 , so that we are able to plot the vectors $x_{i}$ in the form of a map representing $N$ stocks. It may be noted that $x_{i}$ are not necessarily unique under the assumption of the Euclidean metric, as we can arbitrarily translate and rotate them, as long as such transformations leave the distances $\left\|x_{i}-x_{j}\right\|$ unaffected. Generally, MDS can be obtained through an optimization problem, where $\left(x_{1}, \ldots, x_{N}\right)$ 
is the solution of the problem of minimization of a cost function, such as

$$
\min _{x_{1}, \ldots, x_{N}} \sum_{i<j}\left(\left\|x_{i}-x_{j}\right\|-d_{i j}\right)^{2}
$$

In order to capture the sectoral behavior of the market visually, we have generated the MDS plot of 199 stocks as described before, for the time window of 250 trading days between May 2015 - May 2016. As before, using the correlation matrix as input, we computed the distance matrix using the transformations (given by Eq. 11). The distance matrix was then used as an input to the inbuilt MDS function in MATLAB [22]. The output of the MDS were the sets of coordinates, which were plotted as the MDS map as shown in Fig. 6.

The coordinates are plotted in a manner such that the centroid of the map coincides with the origin $(0,0)$. It is interesting to follow the positions of certain sectors: (i) Sugar, (ii) Textiles and (iii) Pharmaceuticals, which will be discussed in details in Section 5.

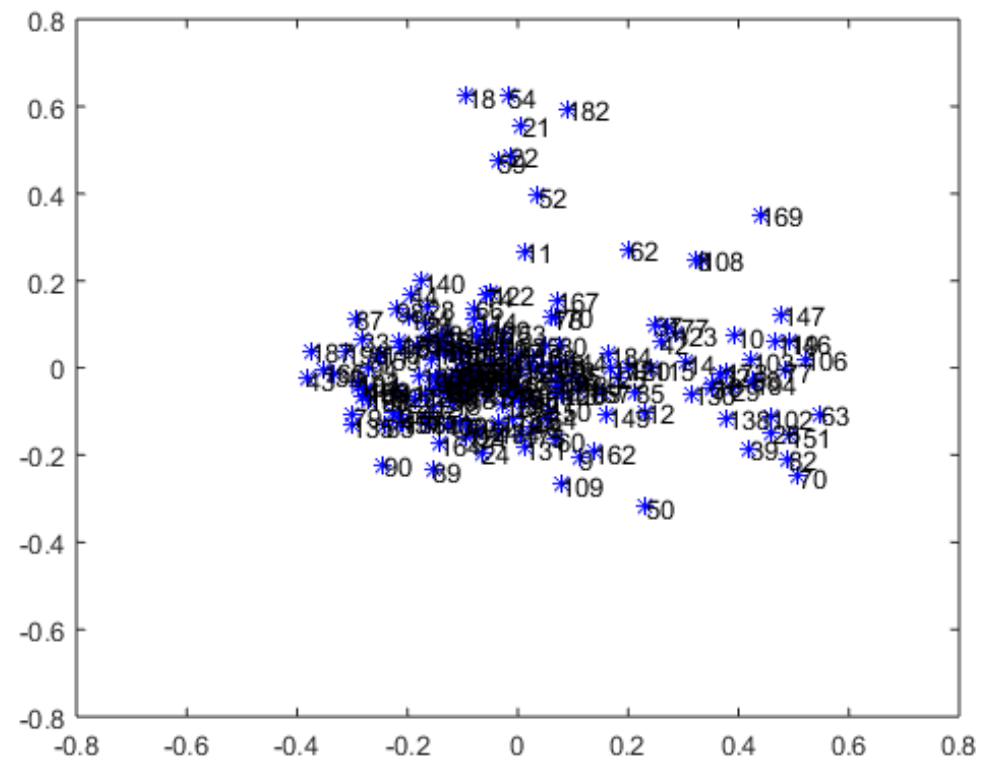

Figure 6: Multidimensional scaling of the sample data for the time window May 2015-May 2016.

\subsection{Dendrogram}

Dendrogram is basically a tree diagram. This is often used to depict the arrangement of multiple nodes through hierarchical clustering. We have used the inbuilt function in MATLAB [23] to generate the hierarchical binary cluster tree (dendrogram) of $N$ stocks connected by many U-shaped lines (as shown in Fig. 7), such that the height of each U represents the distance (given by Eq. 11) between the two data points being connected. Thus, the vertical axis of the tree captures the similarity between different clusters whereas the horizontal axis represents the identity of the objects and clusters. Each joining (fusion) of two clusters is represented on the graph by the splitting of a 
vertical line into two vertical lines. The vertical position of the split, shown by the short horizontal bar, gives the distance (similarity) between the two clusters. We set the property "Linkage Type" as "Wards Minimum Variance", which requires the Distance Method to be Euclidean which results in group formation such that the pooled within-group sum of squares would be minimized. In other words, at every iteration, two clusters in the tree are connected such that it results in the least possible increment in the relevant quantity i.e. pooled within-group sum of squares. Fig. 7 shows the dendrogram of all the 199 stocks clustered in five different colors (by using 'ColorThreshold' property in MATLAB). The magenta color represents the cluster of 'Sugar Industries'.

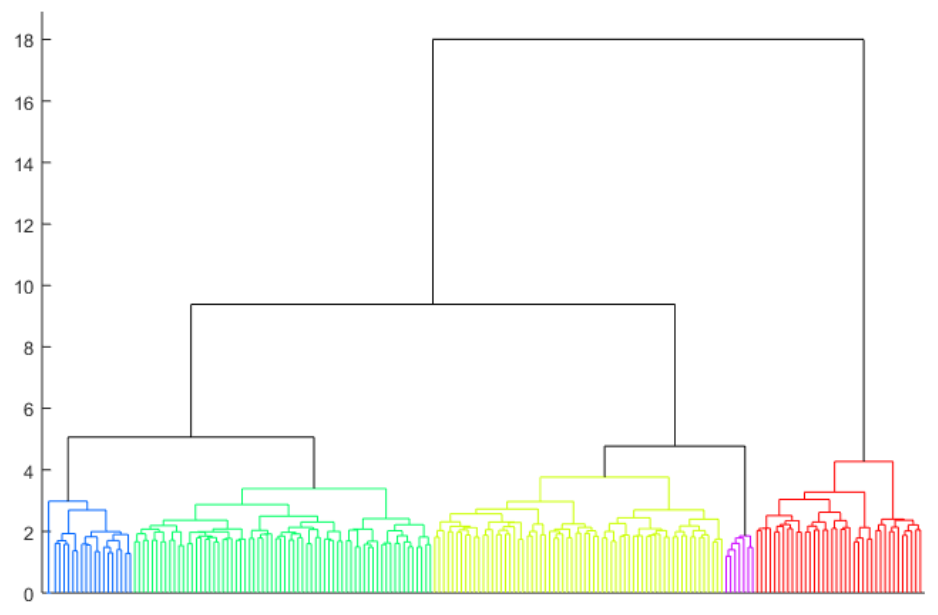

Figure 7: Dendrogram of 199 stocks.

\subsection{Minimum spanning tree}

A minimum spanning tree is a spanning tree of a connected, undirected graph such that all the $N$ vertices are connected together with the minimal total weighting for its $N-1$ edges (total distance is minimum). The distance matrix defined by Eq. 11 was used as an input to the inbuilt MST function in MATLAB [24]. See Matlab documentation for all details. Here we state Kruskal and Prim algorithms for the sake of completeness of the present article. Description of the two algorithms (source: see Ref. [24]):

- Kruskal - This algorithm extends the minimum spanning tree by one edge at every discrete time interval by finding an edge which links two separate trees in a spreading forest of growing minimum spanning trees.

- Prim - This algorithm extends the minimum spanning tree by one edge at every discrete time interval by adding a minimal edge which links a node in the growing minimum spanning tree with one other remaining node. 
Fig. 8 shows the MST for all the 199 stocks. Matlab algorithms set the root node as the first node in the largest connected component, which in our case is node 43.

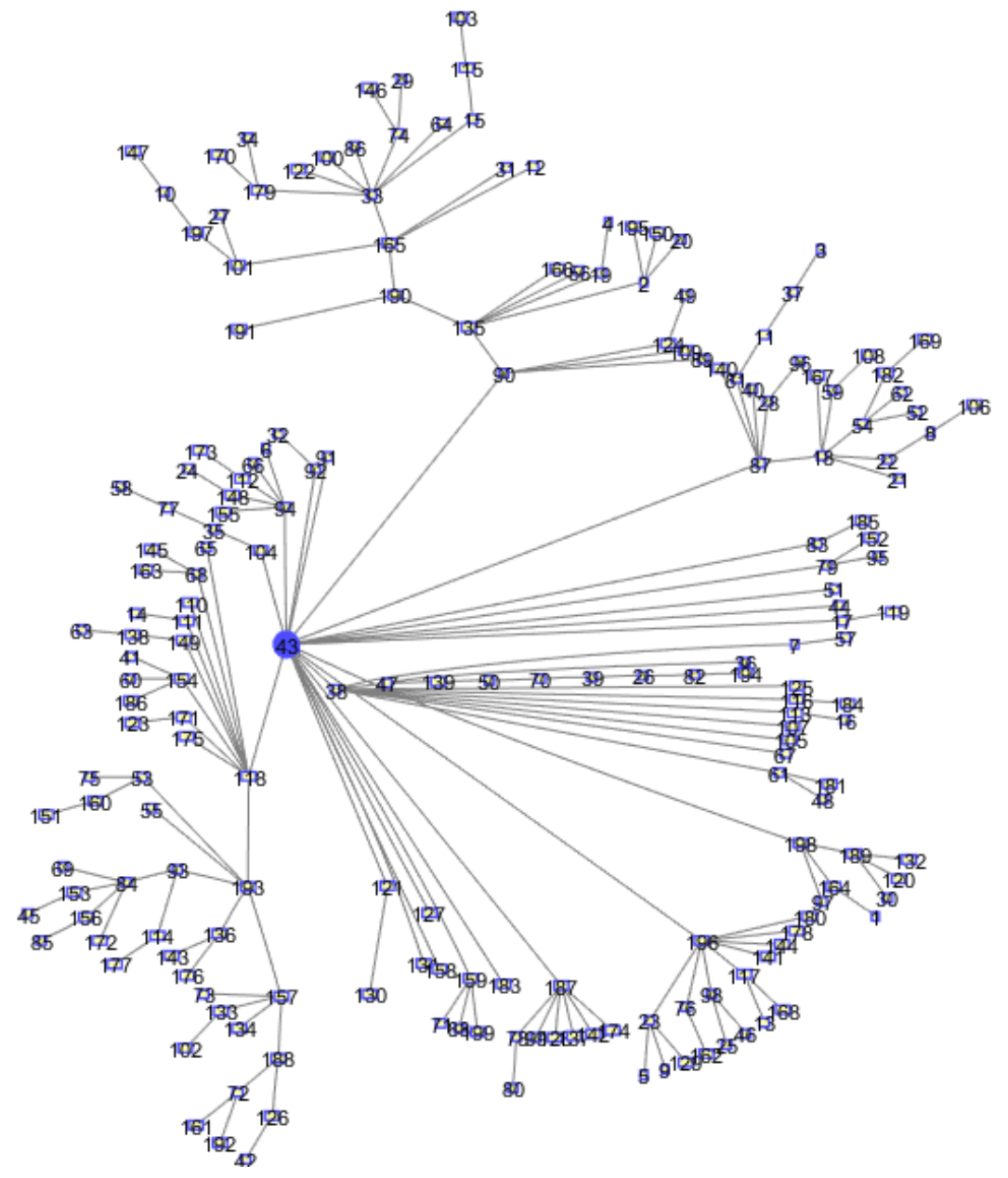

Figure 8: Minimum spanning tree of the sample data.

\section{Sectoral co-movement: mesoscopic network}

After quantifying the general cross-correlation structure of the market, we probe deeper into the sectoral co-movements. There are multiple ways to analyze the data. One, we can impose a threshold on the group cross-correlation matrix and construct a network of stocks which move closely. This is the approach that is followed in [2] for example. This approach has some problems. One, the threshold has to be exogenous and hence, basically arbitrary. Two, even with such networks, it is difficult to identify clusters that matches with actual industry classifications. An alternative way is to follow the industry classifications first and then try to see if they form clusters.

To study the sectoral behavior in the market, we have selected stocks from the list of BSE from the industries: (i) Sugar, (ii) Textiles and (iii) Pharmaceuticals. Following the same methodologies as described in the previous sub-sections 4.2, 4.3 and 4.4, we have generated the plots given in Fig. 


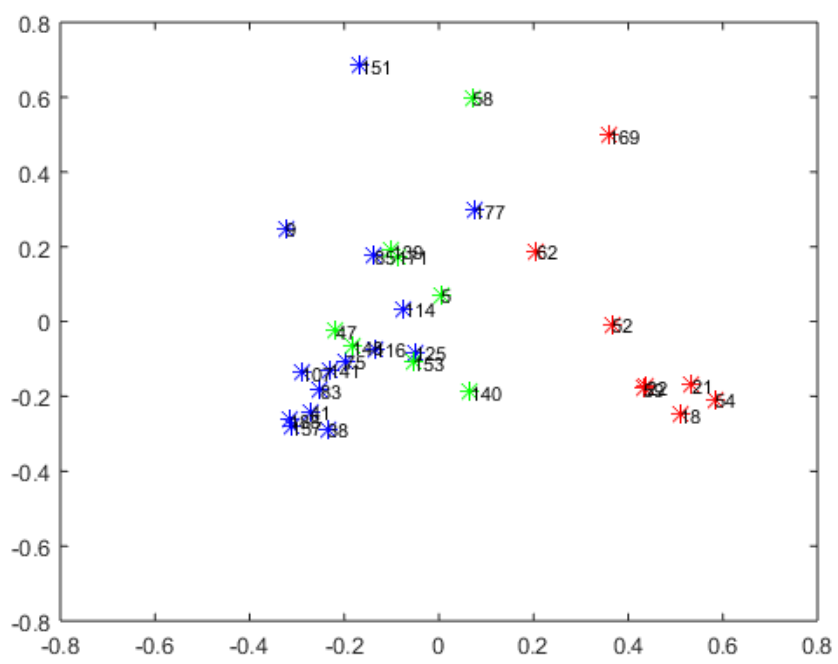

Figure 9: Plot of MDS for the sectors: Sugar (red), Pharmaceuticals (green) and Textiles (blue).

11.

By looking at the diagram, it becomes clear that the method is partially successful to segregate the market into clusters, but not fully. Therefore, we construct a new network. Rather than working with actual stock returns, we work with sectoral index returns.

This marks a prominent departure from the usual mode of analysis. Typically, most studies focus on either an aggregate macro-level market index like S\&P 500, or consider collective dynamics of micro-level individual stock returns. here we consider a mesoscopic network to characterize correlations.

Empirically we used the 13 sectoral indices from the BSE (list given in appendix II) for the time window May 2015-May 2016. The resulting multidimensional scaling results have been plotted in Fig. 12, dendogram in Fig. 13 as well as minimum spanning tree in Fig. 14.

The MDS algorithm cannot segregate the markets into clusters in a way that corresponds to the industry classifications. Dendogram produces better results than that. Finally, the minimum spanning tree corresponds to a fairly intuitive market structure. Note that the only information used was sectoral returns' correlations. The MST shows that the banks and realty sectors are most closely related to the finance sector. Energy sector is most closely associated with oil \& gas sector and so on. Thus we see that the sectoral MST approximates the industrial relations in a fairly correct manner. 


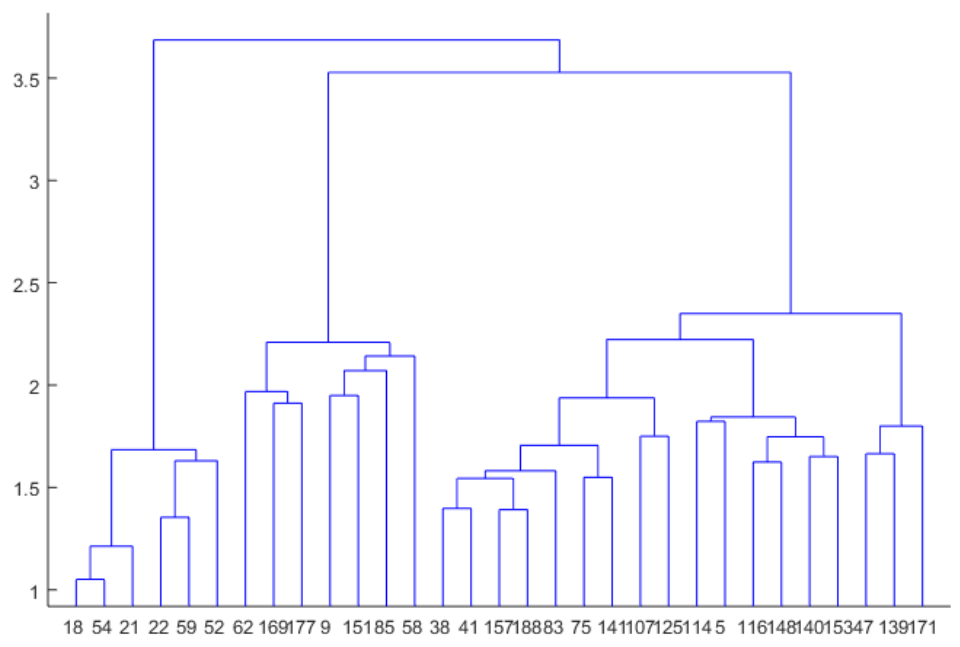

Figure 10: Plot of dendogram for the sectors.

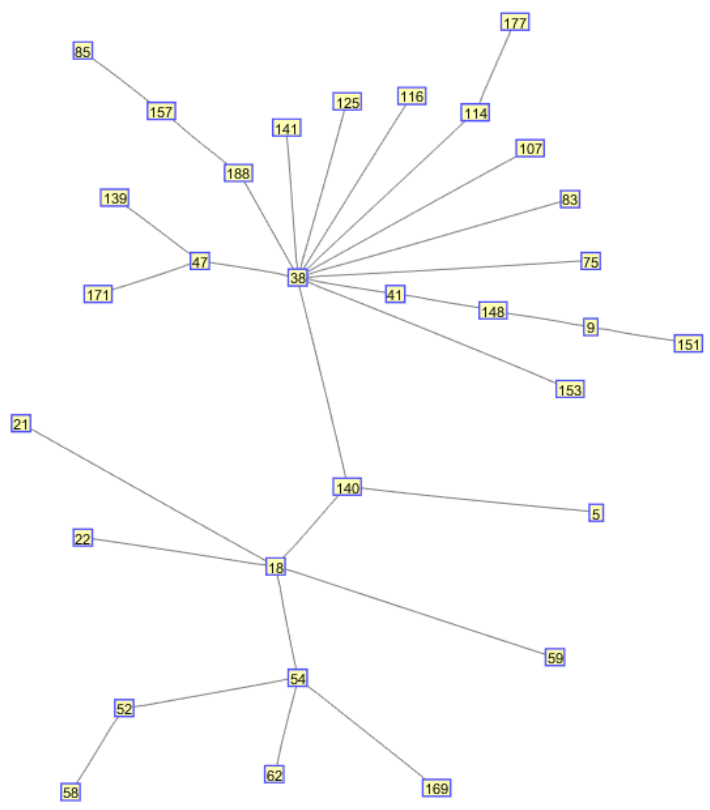

Figure 11: Plot of MST for the sectors. 


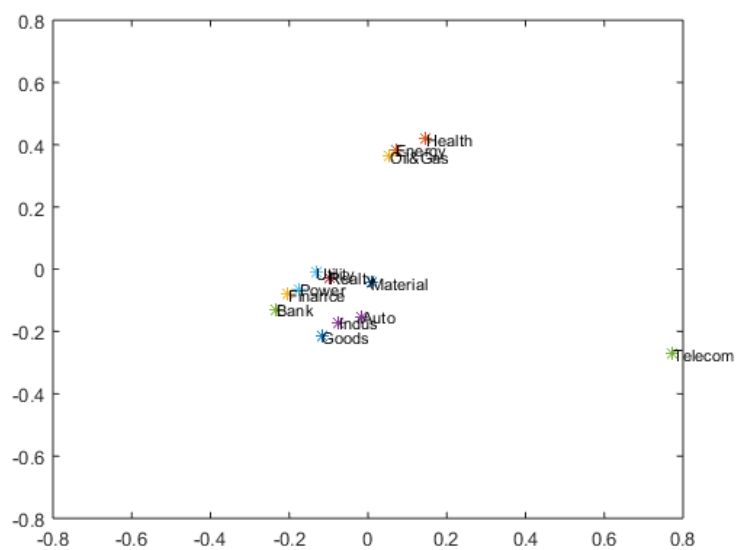

Figure 12: Plot of MDS for the indices.

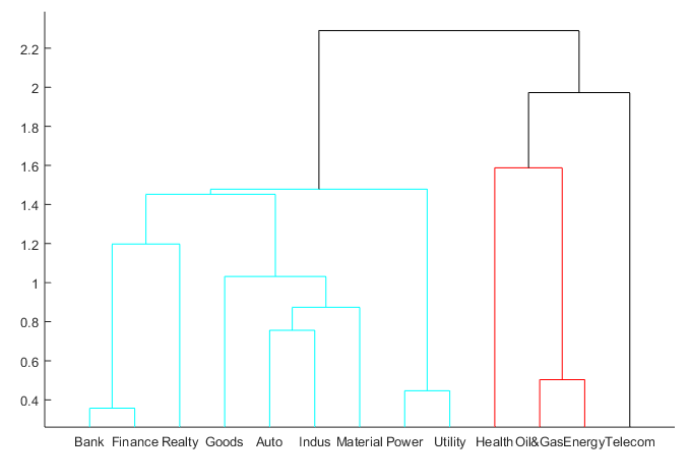

Figure 13: Plot of dendogram for the indices.

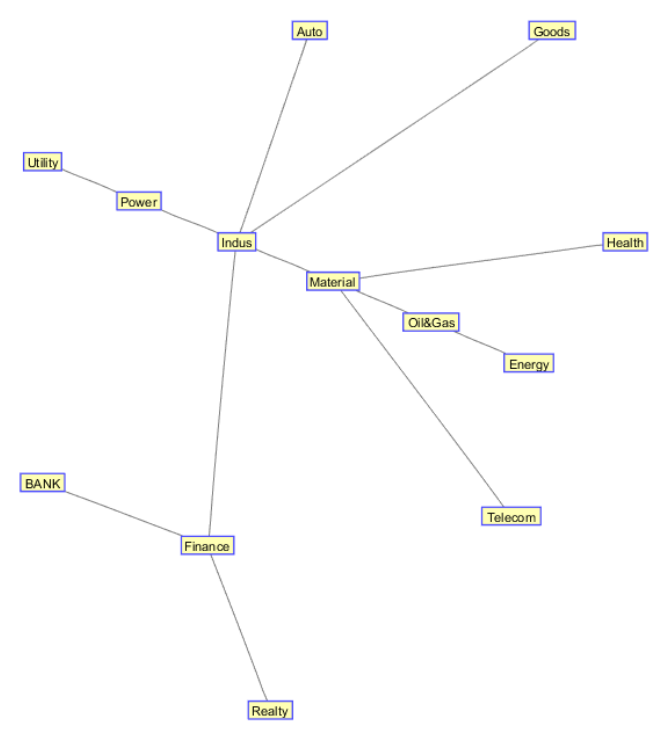

Figure 14: Plot of MST of BSE Indices. 


\section{Summary}

In this article we have applied multiple techniques to analyze daily data from Bombay stock exchange. Our analysis covers a large spectrum of tools proposed in the econophysics literature in the last two decades. Using eigendecomposition method, we show that the market cross-correlation structure shows a very prominent market mode. Consistent with the literature, we show that the group mode is not very strong for emerging countries and in fact, is very difficult to differentiate from the random mode. Then we carry out partial correlation analysis, a newly proposed method, on the Indian data. This helps us to explicitly characterize and quantify the average 'third variable' effect in the cross-correlations.

Finally, we turn to network analysis to study the core-periphery structure. We use multidimensional scaling and dendograms to identify clusters. In general, we do not find any significant pattern between such clusters and the industrial classifications. However, a much more intuitive picture emerges when we construct a mesoscopic network with the sectoral indices. We see that minimum spanning tree across the indices clearly segregates nodes according to their industrial classification, by just using the return cross-correlations.

\section{Acknowledgement}

This research was partially supported by the institute grant, IIM Ahmedabad. KS thanks Univer-

sity Grants Commission (Ministry of Human Research Development, Govt. of India) for her junior research fellowship. AC acknowledges financial support from the institutional research funding IUT (IUT39-1) of the Estonian Ministry of Education and Research, grant number BT/BI/03/004/2003(C) of Govt. of India, Ministry of Science and Technology, Department of Biotechnology, Bioinformatics division, and University of Potential Excellence-II grant (Project ID-47) of the Jawaharlal Nehru University, New Delhi, India. 


\section{Appendix I}

Table 2: List of all sectoral indices. The first column has the abbreviation, the second column has the full name of the sector, as given in the BSE.

\begin{tabular}{|c|c|}
\hline BSESN & S\&P BSE SENSEX \\
\hline SENSEX & S\&P BSE SENSEX \\
\hline BSE500 & S\&P BSE 500 \\
\hline SI1900 & S\&P BSE AUTO \\
\hline SIBANK & S\&P BSE BANKEX \\
\hline SPBSBMIP & S\&P BSE BASIC MATERIALS \\
\hline SI0200 & S\&P BSE CAPITAL GOODS \\
\hline SPBSEIP & S\&P BSE ENERGY \\
\hline SPBSFIIP & S\&P BSE FINANCE \\
\hline SPBSIDIP & S\&P BSE INDUSTRIALS \\
\hline SI1400 & S\&P BSE OIL \& GAS \\
\hline SIPOWE & S\&P BSE POWER \\
\hline SIREAL & S\&P BSE REALTY \\
\hline SPBSTLIP & S\&P BSE TELECOM \\
\hline SPBSUTIP & S\&P BSE UTILITIES \\
\hline SI0800 & S\&P BSE HEALTHCARE \\
\hline
\end{tabular}




\section{Appendix II}

Table 3: List of all stocks considered for the analysis. The first column has the abbreviation, the second column has the full name and the third column specifies the sector as given in the BSE.

\begin{tabular}{|c|c|c|}
\hline $\mathrm{ABB}$ & ABB INDIA LIMITED & Heavy Electrical Equipment \\
\hline ABIRLANUVO & ADITYA BIRLA NUVO LTD. & Diversified \\
\hline AEGISLOG & AEGIS LOGISTICS LTD. & Oil Marketing and Distribution \\
\hline AMARAJABAT & AMARA RAJA BATTERIES LTD. & Auto Parts and Equipment \\
\hline AMBALALSA & $\begin{array}{l}\text { AMBALAL SARABHAI ENTER- } \\
\text { PRISES LTD. }\end{array}$ & Pharmaceuticals \\
\hline ANDHRAPET & $\begin{array}{l}\text { ANDHRA PETROCHEMICALS } \\
\text { LTD. }\end{array}$ & Commodity Chemicals \\
\hline ANSALAPI & $\begin{array}{l}\text { ANSAL PROPERTIES and IN- } \\
\text { FRASTRUCTURE LTD. }\end{array}$ & Realty \\
\hline APPLEFIN & APPLE FINANCE LTD. & Finance (including NBFCs) \\
\hline ARVIND & ARVIND LTD. & Textiles \\
\hline ASIANHOTNR & $\begin{array}{l}\text { ASIAN HOTELS (NORTH) LIM- } \\
\text { ITED }\end{array}$ & Hotels \\
\hline ASSAMCO & $\begin{array}{l}\text { ASSAM COMPANY (INDIA) LIM- } \\
\text { ITED }\end{array}$ & Tea and Coffee \\
\hline ATFL & AGRO TECH FOODS LTD. & Other Agricultural Products \\
\hline ATUL & ATUL LTD. & Agrochemicals \\
\hline ATVPR & ATV PROJECTS INDIA LTD. & Construction and Engineering \\
\hline AUTOLITIND & AUTOLITE (INDIA) LTD. & Auto Parts and Equipment \\
\hline AUTORIDFIN & AUTORIDERS FINANCE LTD. & Finance (including NBFCs) \\
\hline BAJAJELEC & BAJAJ ELECTRICALS LTD. & Household Appliances \\
\hline BAJAJHIND & $\begin{array}{l}\text { BAJAJ HINDUSTHAN SUGAR } \\
\text { LIMITED }\end{array}$ & Sugar \\
\hline BAJFINANCE & BAJAJ FINANCE LIMITED & Finance (including NBFCs) \\
\hline BALLARPUR & BALLARPUR INDUSTRIES LTD. & Paper and Paper Products \\
\hline BALRAMCHIN & $\begin{array}{l}\text { BALRAMPUR CHINI MILLS } \\
\text { LTD. }\end{array}$ & Sugar \\
\hline BANARISUG & $\begin{array}{l}\text { BANNARI AMMAN SUGARS } \\
\text { LTD. }\end{array}$ & Sugar \\
\hline BANCOINDIA & $\begin{array}{l}\text { BANCO PRODUCTS } \\
\text { LTD. }\end{array}$ & Auto Parts and Equipment \\
\hline BASF & BASF INDIA LTD. & Specialty Chemicals \\
\hline BATAINDIA & BATA INDIA LTD. & Footwear \\
\hline
\end{tabular}




\begin{tabular}{|c|c|c|}
\hline BEL & BHARAT ELECTRONICS LTD. & Defence \\
\hline BEML & BEML LTD. & Commercial Vehicles \\
\hline BEPL & $\begin{array}{l}\text { BHANSALI ENGINEERING } \\
\text { POLYMERS LTD. }\end{array}$ & Specialty Chemicals \\
\hline BHAGGAS & BHAGAWATI GAS LIMITED & Industrial Gases \\
\hline BHEL & $\begin{array}{l}\text { BHARAT HEAVY ELECTRICALS } \\
\text { LTD. }\end{array}$ & Heavy Electrical Equipment \\
\hline BHUSANSTL & BHUSHAN STEEL LTD. & Iron and Steel/Interm.Products \\
\hline BIHSPONG & BIHAR SPONGE IRON LTD. & Iron and Steel/Interm.Products \\
\hline BINANIIND & BINANI INDUSTRIES LTD. & Holding Companies \\
\hline BIRLACORPN & $\begin{array}{lll}\text { BIRLA } & \text { CORPORATION } & \text { LIM- } \\
\text { ITED } & & \end{array}$ & Flagship company \\
\hline BIRLAERIC & $\begin{array}{lll}\text { BIRLA } & \text { ERICSSON } & \text { OPTICAL } \\
\text { LTD. } & & \end{array}$ & Other Elect.Equip./ Prod. \\
\hline BLUESTARCO & BLUE STAR LTD. & Consumer Electronics \\
\hline BNKCAP & BNK CAPITAL MARKETS LTD. & Other Financial Services \\
\hline BOMDYEING & $\begin{array}{l}\text { BOMBAY DYEING and } \\
\text { MFG.CO.LTD. }\end{array}$ & Textiles \\
\hline $\mathrm{BPL}$ & BPL LTD. & Consumer Electronics \\
\hline CAMPHOR & $\begin{array}{l}\text { CAMPHOR and ALLIED PROD- } \\
\text { UCTS LTD. }\end{array}$ & Commodity Chemicals \\
\hline CENTENKA & CENTURY ENKA LTD. & Textiles \\
\hline CENTEXT & CENTURY EXTRUSIONS LTD. & Aluminium \\
\hline CENTURYTEX & $\begin{array}{l}\text { CENTURY TEXTILES and IN- } \\
\text { DUSTRIES LTD. }\end{array}$ & Cement and Cement Products \\
\hline CESC & CESC LTD. & Electric Utilities \\
\hline CHAMBLFERT & $\begin{array}{l}\text { CHAMBAL FERTILISERS and } \\
\text { CHEMICALS LTD. }\end{array}$ & Fertilizers \\
\hline CHENNPETRO & $\begin{array}{l}\text { CHENNAI PETROLEUM COR- } \\
\text { PORATION LTD. }\end{array}$ & Refineries/ Petro-Products \\
\hline CIPLA & CIPLA LTD. & Pharmaceuticals \\
\hline CMIFPE & CMI FPE LTD. & Industrial Machinery \\
\hline CRISIL & CRISIL LTD. & Other Financial Services \\
\hline CROMPGREAV & CROMPTON GREAVES LTD. & Heavy Electrical Equipment \\
\hline DABUR & DABUR INDIA LTD. & Personal Products \\
\hline DALMIASUG & $\begin{array}{l}\text { DALMIA BHARAT SUGAR AND } \\
\text { INDUSTRIES LTD }\end{array}$ & Sugar \\
\hline $\mathrm{DCW}$ & DCW LTD. & Petrochemicals \\
\hline DHAMPURSUG & DHAMPUR SUGAR MILLS LTD. & Sugar \\
\hline
\end{tabular}




\begin{tabular}{|c|c|c|}
\hline DIAMINESQ & $\begin{array}{l}\text { DIAMINES and CHEMICALS } \\
\text { LTD. }\end{array}$ & Commodity Chemicals \\
\hline DICIND & DIC INDIA LTD. & Specialty Chemicals \\
\hline DISAQ & DISA INDIA LTD. & Industrial Machinery \\
\hline DRREDDY & $\begin{array}{l}\text { DR.REDDY'S LABORATORIES } \\
\text { LTD. }\end{array}$ & Pharmaceuticals \\
\hline EIDPARRY & E.I.D.-PARRY (INDIA) LTD. & Sugar \\
\hline ELANTAS & ELANTAS BECK INDIA LTD. & Commodity Chemicals \\
\hline ELECTCAST & $\begin{array}{l}\text { ELECTROSTEEL CASTINGS } \\
\text { LTD. }\end{array}$ & Construction and Engineering \\
\hline EMPEESUG & $\begin{array}{l}\text { EMPEE SUGARS and CHEMI- } \\
\text { CALS LTD. }\end{array}$ & Sugar \\
\hline ENVAIREL & ENVAIR ELECTRODYNE LTD. & Industrial Machinery \\
\hline ESABINDIA & ESAB INDIA LTD. & Other Industrial Goods \\
\hline ESSELPRO & ESSEL PROPACK LTD. & Containers and Packaging \\
\hline ESTER & ESTER INDUSTRIES LTD. & Commodity Chemicals \\
\hline EXIDEIND & EXIDE INDUSTRIES LTD. & Auto Parts and Equipment \\
\hline FEDDERLOYD & $\begin{array}{l}\text { FEDDERS LLOYD CORPORA- } \\
\text { TION LTD. }\end{array}$ & Other Elect.Equip./ Prod. \\
\hline FERROALL & $\begin{array}{l}\text { FERRO ALLOYS CORPORA- } \\
\text { TION LTD. }\end{array}$ & Iron and Steel/Interm.Products \\
\hline FGP & FGP LTD. & Finance (including NBFCs) \\
\hline FINCABLES & FINOLEX CABLES LTD. & Other Elect.Equip./ Prod. \\
\hline FORCEMOT & FORCE MOTORS LTD. & Cars and Utility Vehicles \\
\hline FOSECOIND & FOSECO INDIA LTD. & Commodity Chemicals \\
\hline GANESHBE & GANESH BENZOPLAST LTD. & Commodity Chemicals \\
\hline GARDENSILK & GARDEN SILK MILLS LTD. & Textiles \\
\hline GHCL & GHCL LTD. & Commodity Chemicals \\
\hline GLFL & $\begin{array}{l}\text { GUJARAT LEASE FINANCING } \\
\text { LTD. }\end{array}$ & Finance (including NBFCs) \\
\hline GODFRYPHLP & $\begin{array}{l}\text { GODFREY PHILLIPS INDIA } \\
\text { LTD. }\end{array}$ & Cigarettes-Tobacco Products \\
\hline GODREJIND & GODREJ INDUSTRIES LTD. & Commodity Chemicals \\
\hline GOLDENTOBC & GOLDEN TOBACCO LTD. & Cigarettes-Tobacco Products \\
\hline GOODRICKE & GOODRICKE GROUP LTD. & Tea and Coffee \\
\hline GOODYEAR & GOODYEAR INDIA LTD. & Auto Tyres and Rubber Products \\
\hline GRASIM & GRASIM INDUSTRIES LTD. & Textiles \\
\hline GTL & GTL LTD. & Other Telecom Services \\
\hline GTNINDS & GTN INDUSTRIES LTD. & Textiles \\
\hline
\end{tabular}




\begin{tabular}{|c|c|c|}
\hline GUJFLUORO & $\begin{array}{l}\text { GUJARAT FLUOROCHEMICALS } \\
\text { LTD. }\end{array}$ & Industrial Gases \\
\hline $\mathrm{HCC}$ & $\begin{array}{l}\text { HINDUSTAN CONSTRUCTION } \\
\text { CO.LTD. }\end{array}$ & Construction and Engineering \\
\hline HCIL & $\begin{array}{l}\text { HIMADRI CHEMICALS and IN- } \\
\text { DUSTRIES LTD. }\end{array}$ & Commodity Chemicals \\
\hline HDFC & $\begin{array}{l}\text { HOUSING DEVELOPMENT FI- } \\
\text { NANCE CORP.LTD. }\end{array}$ & Housing Finance \\
\hline HDFCBANK & HDFC BANK LTD & Banks \\
\hline HEIDELBERG & $\begin{array}{l}\text { HEIDELBERGCEMENT INDIA } \\
\text { LTD. }\end{array}$ & Cement and Cement Products \\
\hline HEROMOTOCO & HERO MOTOCORP LTD. & $2 / 3$ Wheelers \\
\hline HFCL & $\begin{array}{l}\text { HIMACHAL FUTURISTIC COM- } \\
\text { MUNICATIONS LTD. }\end{array}$ & Telecom Cables \\
\hline HINDOILEXP & $\begin{array}{l}\text { HINDUSTAN OIL EXPLO- } \\
\text { RATION CO.LTD. }\end{array}$ & Exploration and Production \\
\hline HINDPETRO & $\begin{array}{l}\text { HINDUSTAN PETROLEUM } \\
\text { CORPORATION LTD. }\end{array}$ & Refineries/ Petro-Products \\
\hline HINDUJAVEN & HINDUJA VENTURES LTD. & Broadcasting and Cable TV \\
\hline HINDZINC & HINDUSTAN ZINC LTD. & Zinc \\
\hline HMT & HMT LTD. & Commercial Vehicles \\
\hline HOTELEELA & HOTEL LEELAVENTURE LTD. & Hotels \\
\hline HSIL & HSIL LTD. & Containers and Packaging \\
\hline IDBI & IDBI BANK LTD. & Banks \\
\hline IFCI & IFCI LTD. & Financial Institutions \\
\hline IFSL & $\begin{array}{l}\text { INTEGRATED FINANCIAL SER- } \\
\text { VICES LTD. }\end{array}$ & Finance (including NBFCs) \\
\hline IGPL & I G PETROCHEMICALS LTD. & Commodity Chemicals \\
\hline INDIAGLYCO & INDIA GLYCOLS LTD. & Commodity Chemicals \\
\hline INDLEASE & $\begin{array}{l}\text { INDIA LEASE DEVELOPMENT } \\
\text { LTD. }\end{array}$ & Finance (including NBFCs) \\
\hline INDORAMA & $\begin{array}{l}\text { INDO RAMA SYNTHETICS (IN- } \\
\text { DIA) LTD. }\end{array}$ & Textiles \\
\hline INDSUCR & INDIAN SUCROSE LTD. & Beverage Store \\
\hline INFY & INFOSYS LTD. & IT Consulting and Software \\
\hline INGERRAND & $\begin{array}{l}\text { INGERSOLL-RAND } \\
\text { LTD. }\end{array}$ & Industrial Machinery \\
\hline INSILCO & INSILCO LTD. & Other Industrial Goods \\
\hline IONEXCHANG & ION EXCHANGE (INDIA) LTD. & Industrial Machinery \\
\hline
\end{tabular}




\begin{tabular}{|c|c|c|}
\hline ITHL & $\begin{array}{l}\text { INTERNATIONAL } \\
\text { HOUSE LTD. }\end{array}$ & Travel Support Services \\
\hline JASCH & JASCH INDUSTRIES LTD. & Textiles \\
\hline JAYKAY & JAYKAY ENTERPRISES LTD. & Finance (including NBFCs) \\
\hline JCTLTD & JCT LTD. & Textiles \\
\hline JINDALPOLY & JINDAL POLY FILMS LTD. & Commodity Chemicals \\
\hline JISLJALEQS & $\begin{array}{lll}\text { JAIN } & \text { IRRIGATION } & \text { SYSTEMS } \\
\text { LTD. } & & \\
\end{array}$ & Plastic Products \\
\hline JKLAKSHMI & JK LAKSHMI CEMENT LTD. & Cement and Cement Products \\
\hline JSWSTEEL & JSW STEEL LTD. & Iron and Steel/Interm.Products \\
\hline KAJARIACER & KAJARIA CERAMICS LTD. & Furniture-Furnishing-Paints \\
\hline KAKATCEM & $\begin{array}{l}\text { KAKATIYA CEMENT } \\
\text { and INDUSTRIES LTD. }\end{array}$ & Cement and Cement Products \\
\hline KANELIND & KANEL INDUSTRIES LTD. & Comm.Trading and Distribution \\
\hline KANSAINER & $\begin{array}{lll}\text { KANSAI NEROLAC } & \text { PAINTS } \\
\text { LTD. } & & \\
\end{array}$ & Furniture-Furnishing-Paints \\
\hline KGDENIM & KG DENIM LTD. & Textiles \\
\hline KINETICENG & KINETIC ENGINEERING LTD. & $2 / 3$ Wheelers \\
\hline KIRLFER & $\begin{array}{l}\text { KIRLOSKAR FERROUS INDUS- } \\
\text { TRIES LTD. }\end{array}$ & Iron and Steel/Interm.Products \\
\hline KIRLOSBROS & KIRLOSKAR BROTHERS LTD. & Industrial Machinery \\
\hline KIRLOSIND & KIRLOSKAR INDUSTRIES LTD. & Industrial Machinery \\
\hline KOTAKBANK & KOTAK MAHINDRA BANK LTD. & Banks \\
\hline KSBPUMPS & KSB PUMPS LTD. & Industrial Machinery \\
\hline KSL & KALYANI STEELS LTD. & Iron and Steel/Interm.Products \\
\hline LAXMIMACH & $\begin{array}{l}\text { LAKSHMI MACHINE WORKS } \\
\text { LTD. }\end{array}$ & Industrial Machinery \\
\hline LGBBROSLTD & $\begin{array}{l}\text { L.G.BALAKRISHNAN and } \\
\text { BROS.LTD. }\end{array}$ & Auto Parts and Equipment \\
\hline LICHSGFIN & LIC HOUSING FINANCE LTD. & Housing Finance \\
\hline LML & LML LTD. & $2 / 3$ Wheelers \\
\hline LOKHSG & $\begin{array}{l}\text { LOK HOUSING and CONSTRUC- } \\
\text { TIONS LTD. }\end{array}$ & Realty \\
\hline LORDSCHLO & LORDS CHLORO ALKALI LTD. & Commodity Chemicals \\
\hline LUPIN & LUPIN LTD. & Pharmaceuticals \\
\hline LYKALABS & LYKA LABS LTD. & Pharmaceuticals \\
\hline MAFATIND & MAFATLAL INDUSTRIES LTD. & Textiles \\
\hline MAHSCOOTER & $\begin{array}{l}\text { MAHARASHTRA SCOOTERS } \\
\text { LTD. }\end{array}$ & $2 / 3$ Wheelers \\
\hline
\end{tabular}




\begin{tabular}{|c|c|c|}
\hline MAHSEAMLES & $\begin{array}{l}\text { MAHARASHTRA SEAMLESS } \\
\text { LTD. }\end{array}$ & Construction and Engineering \\
\hline MAJESAUT & MAJESTIC AUTO LTD. & 2/3 Wheelers \\
\hline MANALIPETC & $\begin{array}{l}\text { MANALI PETROCHEMICAL } \\
\text { LTD. }\end{array}$ & Petrochemicals \\
\hline MARGOFIN & MARGO FINANCE LTD. & Finance (including NBFCs) \\
\hline MAVIIND & MAVI INDUSTRIES LTD. & Plastic Products \\
\hline MERCK & MERCK LTD. & Pharmaceuticals \\
\hline METROGLOBL & METROGLOBAL LTD. & Paper and Paper Products \\
\hline MFSL & $\begin{array}{lll}\text { MAX } & \text { FINANCIAL } & \text { SERVICES } \\
\text { LTD. } & & \end{array}$ & Life Insurance \\
\hline MIDINDIA & MID INDIA INDUSTRIES LTD. & Textiles \\
\hline MIRCELECTR & MIRC ELECTRONICS LTD. & Consumer Electronics \\
\hline MOREPENLAB & $\begin{array}{l}\text { MOREPEN LABORATORIES } \\
\text { LTD. }\end{array}$ & Pharmaceuticals \\
\hline MRF & MRF LTD. & Auto Tyres and Rubber Products \\
\hline MRPL & $\begin{array}{l}\text { MANGALORE REFINERY and } \\
\text { PETROCHEMICALS LTD. }\end{array}$ & Refineries/ Petro-Products \\
\hline MTNL & $\begin{array}{ll}\text { MAHANAGAR } & \text { TELEPHONE } \\
\text { NIGAM LTD. } & \end{array}$ & Telecom Services \\
\hline NAHARSPING & NAHAR SPINNING MILLS LTD. & Textiles \\
\hline NATPEROX & NATIONAL PEROXIDE LTD. & Commodity Chemicals \\
\hline NCC & NCC LTD. & Construction and Engineering \\
\hline NEPCMICON & NEPC INDIA LTD. & Heavy Electrical Equipment \\
\hline NIITLTD & NIIT LTD. & IT Training Services \\
\hline NIRLON & NIRLON LTD. & Misc.Commercial Services \\
\hline OILCOUNTUB & OIL COUNTRY TUBULAR LTD. & Oil \\
\hline ONGC & $\begin{array}{l}\text { OIL AND NATURAL GAS COR- } \\
\text { PORATION LTD. }\end{array}$ & Oil and Gas \\
\hline ORIENTBANK & $\begin{array}{llll}\text { ORIENTAL } & \text { BANK } & \text { OF } & \text { COM- } \\
\text { MERCE } & & & \\
\end{array}$ & Banks \\
\hline ORIENTHOT & ORIENTAL HOTELS LTD. & Hotels \\
\hline OSWALAGRO & OSWAL AGRO MILLS LTD. & Real Estate \\
\hline PANCM & $\begin{array}{l}\text { PANYAM CEMENTS AND MIN- } \\
\text { ERAL INDS. }\end{array}$ & Cement and Cement Products \\
\hline PARRYSUGAR & $\begin{array}{l}\text { PARRYS SUGAR INDUSTRIES } \\
\text { LTD. }\end{array}$ & Sugar \\
\hline PDUMJEPULP & $\begin{array}{l}\text { PUDUMJEE PULP AND PAPER } \\
\text { MILLS LTD. }\end{array}$ & Paper and Paper Products \\
\hline
\end{tabular}




\begin{tabular}{|c|c|c|}
\hline PEL & PIRAMAL ENTERPRISES LTD. & Pharmaceuticals \\
\hline PENTAGRAPH & PENTAMEDIA GRAPHICS LTD. & Graphics \\
\hline PHCAP & PH CAPITAL LTD. & Comm.Trading and Distribution \\
\hline PIDILITIND & PIDILITE INDUSTRIES LTD. & Manufacturer \\
\hline PILITA & PIL ITALICA LIFESTYLE LTD. & Plastic Furniture Manufacturers \\
\hline PIXTRANS & PIX TRANSMISSIONS LTD. & $\begin{array}{l}\text { Manufacturer of Industrial Belts, } \\
\text { Automotive Belts and Agricultural } \\
\text { Belts }\end{array}$ \\
\hline PRAGBOS & $\begin{array}{l}\text { PRAG BOSIMI SYNTHETICS } \\
\text { LTD. }\end{array}$ & Textiles \\
\hline PRIMESECU & PRIME SECURITIES LTD. & Security \\
\hline PRISMCEM & PRISM CEMENT LTD.? & Cement and Cement Products \\
\hline PUNJCOMMU & $\begin{array}{l}\text { PUNJAB COMMUNICATIONS } \\
\text { LTD. }\end{array}$ & Communication \\
\hline RAIN & RAIN INDUSTRIES LTD. & Rain Cements Limited \\
\hline RAJSREESUG & $\begin{array}{l}\text { RAJSHREE SUGAR AND CHEM- } \\
\text { ICAL LTD. }\end{array}$ & Sugar \\
\hline RALLIS & $\begin{array}{l}\text { RALLIS INDIA LIMITED- NITYA } \\
\text { AGRO SERVICES }\end{array}$ & Agrochemicals Supplier \\
\hline RAMANEWS & $\begin{array}{lll}\text { SHREE } & \text { RAMA } & \text { NEWSPRINT } \\
\text { LTD. } & & \\
\end{array}$ & Newsprint and Papers \\
\hline RAMCOCEM & THE RAMCO CEMENTS LTD. & Cement and Cement Products \\
\hline RAYMOND & RAYMOND GROUP & Fabrics \\
\hline RELCAPITAL & RELIANCE CAPITAL LTD. & Finance (including NBFCs) \\
\hline RSWM & R S W M Ltd. & Textiles \\
\hline SAIL & $\begin{array}{l}\text { STEEL AUTHORITY OF INDIA } \\
\text { LTD. }\end{array}$ & Iron and Steel/Interm.Products \\
\hline SBI & STATE BANK OF INDIA & Banks \\
\hline SBIN & STATE BANK OF INDIA & Banks \\
\hline SPICEJET & SPICEJET LTD. & Airlines \\
\hline SURYAROSNI & SURYA ROSHNI LTD. & Misc.Commercial Services \\
\hline TITAN & TITAN COMPANY LTD. & Other Apparels and Accessories \\
\hline TRENT & TRENT LTD. & Department Stores \\
\hline UFLEX & UFLEX LTD. & Containers and Packaging \\
\hline UMANGDAIR & UMANG DAIRIES LTD. & Packaged Foods \\
\hline VEDL & VEDANTA LTD. & Iron and Steel/Interm.Products \\
\hline WHIRLPOOL & WHIRLPOOL OF INDIA LTD. & Consumer Electronics \\
\hline
\end{tabular}




\section{References}

[1] C. Kuyyamudi, A. S. Chakrabarti, S. Sinha, Long-term evolution of the topological structure of interactions among stocks in the New York Stock Exchange 1925-2012, Econophysics and Data Driven Modelling of Market Dynamics, Eds, F. Abergel et al, Springer-Verlag, Milan (2015).

[2] R. K. Pan, S. Sinha, Collective behavior of stock price movements in an emerging market, Physical Review E 76, 046116 (2007).

[3] N. Marwan, Cross Recurrence Plot Toolbox for MATLAB, Ver. 5.20 (R30.4), http://tocsy.pikpotsdam.de/CRPtoolbox/, accessed 2016-06-22.

[4] N. Marwan, M. C. Romano, J. Thiel, J. Kurths, Recurrence Plots for the Analysis of Complex Systems, Physics Reports, 438(5-6), 2007, 237-329.

[5] R. Mantegna, H. E. Stanley, Introduction to Econophysics Cambridge University Press, Cambridge, UK, 1999.

[6] J. P. Bouchaud, M.Potters, Theory of Financial Risk and Derivative Pricing: From Statistical Physics to Risk Management, Cambridge University Press (2009)

[7] W. Baumol, J. Benhabib, Chaos: Significance, Mechanism, and Economic Applications, Journal of Economic Perspectives 3: 77-105 (1989).

[8] W. Brock, C. Sayers, Is The Business Cycle Characterized by Deterministic Chaos? Journal of Monetary Economics 22: 71-90 (1988).

[9] F. takens, Detecting strange attractors in turbulence in: D. Rand, L. Young (eds), Dynamicl systems and Turbuence, Springer, Berlin, p. 366-381 (1981).

[10] J. A. Bastos, J. Caiddo, Recurrence quantification analysis of global stock markets, Physica A 390, 7 1, 13151325 (2011).

[11] K. Guhathakurta, B, Bhattacharya, A. Roy Chowdhury, Using recurrence plot analysis to distinguish between endogenous and exogenous stock market crashes, Physica A 389, 9, 18741882 (2010).

[12] D. Sornette, Why stock markets crash?, Princeton University Press (2004)

[13] D. Kenett, X. Huang, I. Vodensk, S. Havlin and H. E. Stanley, Partial correlation analysis: applications for financial markets, Quantitative Finance, 15 (4) 569-578.

[14] https://in finance $\cdot$ yahoo $\cdot$ com/q/hp?s=\%5EBSESN 
[15] A. Chakraborti, An Outlook on Correlations in Stock Prices, in Eds. A. Chatterjee and B.K. Chakrabarti, Econophysics of Stock and other Markets (Springer- Verlag (Italia), Milan, 2006); available at arXiv:physics/0605246 (2006).

[16] G. Tilak, T. Szell, R. Chicheportiche and A. Chakraborti, Study of statistical correlations in intraday and daily financial return time series, Econophysics of systemic risk and network dynamics, Eds. F. Abergelet al, Springer-Verlag, Milan, (2012).

[17] R. Rammal, G. Toulouse, and M. A. Virasoro, Ultrametricity for physicists, Rev. Mod. Phys. 58,765 (1986)

[18] R.N. Mantegna, Eur. Phys. J. B 11, 193 (1999).

[19] J. P. Onnela, A. Chakraborti, K. Kaski, J. Kertesz and A. Kanto, Dynamics of market correlations: Taxonomy and portfolio analysis, Physical Review E 68, 056110 (2003).

[20] J.-P. Onnela, A. Chakraborti, K. Kaski, J. Kertesz and A. Kanto, Physica Scripta T 106, 48 (2003).

[21] I. Borg and P. Groenen, Modern Multidimensional Scaling: theory and applications (SpringerVerlag, New York, 2005)

[22] http://in.mathworks.com/help/stats/cmdscale.html

[23] http://in.mathworks.com/help/stats/dendrogram.html

[24] http://in.mathworks.com/help/bioinfo/ref/graphminspantree.html 